\title{
A Critical Review of Prominent Theories of Politeness
}

\author{
Hutheifa Y. Al-Duleimi (Corresponding author) \\ Department of English, Faculty of Modern Languages and Communication, University Putra Malaysia, 43000, Serdang, Selangor, Malaysia \\ E-mail: hu1978da@yahoo.com \\ Sabariah Md. Rashid \\ Department of English, Faculty of Modern Languages and Communication, University Putra Malaysia, 43000, Serdang, Selangor, Malaysia \\ E-mail: smrashid@upm.edu.my \\ Ain Nadzimah Abdullah \\ Department of English, Faculty of Modern Languages and Communication, University Putra Malaysia, 43000, Serdang, Selangor, Malaysia \\ E-mail: ain@upm.edu.my
}

Doi:10.7575/aiac.alls.v.7n.6p.262

URL: http://dx.doi.org/10.7575/aiac.alls.v.7n.6p.262
Received: 05/10/2016

Accepted: 28/11/2016

\begin{abstract}
Politeness plays a crucial role in all cultures and societies for maintaining relationships and for face saving. Although politeness is common to all cultures and languages, how it functions and is realised varies from one culture to another. Different theories have been proposed to examine the strategies with which politeness is expressed. Each theory has weak and strong points which may make it appropriate to a culture but not to another. The most widely used of these theories are Brown and Levinson's (1978) and its modified version (1987), Lakoff's (1973), and Leech's (1983, 2005) theories of politeness. This paper aims to provide a critical review of the aforementioned theories. Specifically, it discusses different scholars' viewpoints on these theories, highlighting the weak and strong points of the theories. Accordingly, it examines the applicability of these theories to the East and West cultures. A review of these theories indicated that they have weak points as well as strong ones. Furthermore, they might not be suitable for all cultures. This confirms that politeness is a social behaviour not specific to one culture or language. Critical review revealed that Leech's (2005) Grand Strategy of Politeness might be the most applicable theory that could cover aspects of Eastern and Western cultures.
\end{abstract}

Keywords: prominent politeness theories, Eastern culture, Western culture

\section{Introduction}

To begin with, politeness is not a natural phenomenon. It exists as a result of interactions between people and culture (Reiter, 2000, pp. 1-2), and politeness is acquired with the passage of time through the sociocultural coexistence of people with one another. People perform functions of politeness to various degrees to successfully communicate with each other. They use it to minimise the force of their speech acts. Therefore, different theories have been proposed to cover how politeness is involved in any act of communication. This paper provides a review of Brown and Levinson's (1987), Lakoff's (1973), and Leech's $(1983,2005)$ theories of politeness as they are most widely used.

To shed light on the different viewpoints of different theories of politeness, Terkourafi (2005) presented a very important distinction between two groups of theories of politeness: the traditional theories of politeness presented by Brown and Levinson (1987), Lakoff (1973), and Leech (1983), and the new theories, which were proposed by Elen (2001), Mills (2003), and Watts (2003). Whilst the first group of theories dealt with politeness as a social phenomenon, it was based on Grice's theory of cooperative maxims and the theory of speech acts, which focused on the speaker's intention as abstracted from the actual performance. This means that the theories advocated the speaker's face orientation. The first group of scholars assumed that since they agreed with the claim that politeness is a general social phenomenon, cultures are internally homogenous, though they are different. Consequently, the scholars came out with the claim that face and the principles of politeness are universal (Terkourafi, 2005).

In reaction to these claims, the second group of scholars focused on the structure and nature of politeness norms across different cultures. They believed in the heterogeneity of politeness across cultures or within cultures. In light of this heterogeneity, the universality of politeness principles might not be appropriate to all cultures and, in addition, in contrast to the theories proposed by the first group, the role of the addressee became vital and important in the judgment of politeness. Furthermore, politeness no longer referred only to the strategies used between speaker and hearer. It was modified to include the study of the exchanges occurring in certain situations (Terkourafi, 2005). Accordingly, Leech (2005) proposed his new theory of the Grand Strategy of Politeness in which he modified his old theory of politeness 
(1983) to cover the strategies of politeness and the social factors that influenced their use in any act of communication in cultures other than Western.

Accordingly, it can be said that politeness is not a natural phenomenon, but it is acquired gradually and programmed in terms of social norms in the mind of the individual who is going to express them through his behaviour .This indicates that the social rules of a society are specific for that society, and the rules enable the individual to use his speech acts appropriately. These rules include the ways that members of a certain society adhere to in expressing politeness towards each other. For example, social distance involves the individual to be formal in his speech (Reiter, 2000, p. 6).

Despite this thread of information, knowledge about politeness across different languages and cultures is still premature because of the fact that politeness is universal as a concept but not as a behaviour. Furthermore, the appearance of an adequate theory of politeness covering the characteristics of most Western and Eastern languages might still be under research and might not be applicable to other cultures. With this in mind, this study aimed to shed light on the main concerns of the most prominent theories of politeness (Brown \& Levinson, 1987; Lakoff, 1973, 1975; Leech, 1983, 2005). It examined the merits and demerits, and the different viewpoints of these theories that might help a researcher adopt an adequate theory of politeness in future related studies.

However, since the aim of the current study is to provide a critical review of the most prominent theories of politeness - Brown and Levinson (1987), Lakoff $(1973,1975)$, and Leech $(1983,2005)$ - the review focuses on explaining the essence of each theory and discussing any shortcomings and/or merits of each theory that have been raised by other scholars. The different viewpoints proposed by these theories are compared to what was said by other scholars about whether politeness might be universal to all cultures or not. Also, the researchers reviewed studies that might indicate whether there was an adequate theory of politeness that could be applicable in the East as well as in the West.

\section{What is politeness?}

The term politeness means to take hearers' feelings and desires into consideration when speaking and acting. This means that politeness could be expressed verbally and non-verbally in actions (Leech, 1983, p. 140). In other words, politeness could be expressed, for example, through dressing appropriately, and using appropriate "facial expressions, gestures or bodily postures" (Ashizuka, Mima, Sawamoto, Aso, Oishi, Sugihara, \& Fukuyama, 2015, p. 1). It could further be expressed verbally using honorific language represented through certain linguistic forms of a particular language, such as in Japanese (Fukada \& Asato, 2004; Yoshimura \& MacWhinney, 2011). According to Thomas (1995, p. 158), politeness plays an effective role in interaction because it controls the cooperative behaviour in conversation. Thus, politeness strategies are used by speakers to maintain harmony between them.

Consequently, it was pointed out that the more formal the context, the more powerful would be the relation between interlocutors. In fact, the unequal relation between interlocutors results in a high distance between them (Holems, 1995, p. 19). Thus, in considering politeness, individuals are allowed to "avoid friction" in any act of face-to-face communication, and this, in turn, might lead individuals to communicate successfully (Ermida, 2006, p. 844). In this regard, Holmes (2001, p. 268) confirmed that for the speaker to be polite or impolite linguistically, he is required to speak according to the relationship that relates him to the hearer. Therefore, making decisions about what is polite or impolite in any community depends on two factors. First is an assessment of the social relationship between interlocutors along the dimensions of power and solidarity. As Fairclough (1989, p. 66) emphasises, "politeness is based on the recognition of differences of power, degree of social distance," or solidarity. Second is the knowledge of the social values and norms of the community. Accordingly, for further details, the researchers allocated a review, in the following sections, of the most important theories of politeness that might help in understanding how politeness functions between interlocutors of similar and/or different social relations.

\section{Lakoff's rules of politeness}

Amongst those who were first to conduct studies on politeness was Lakoff (1973). In her theory of politeness, she accounted for politeness in terms of adopting Grice's conversational maxims, which were characterised by their universal constructs. In her attempt to expand on Grice's view, two basic rules were proposed: 1) be clear, and 2) be polite. Lakoff states that grammar does not concern only the acceptability and the applicability of grammatical rules, but should also exceed that to include pragmatic aspects (1975, p. 296). Through her proposed rules of politeness, Lakoff (1973) attempted to create an integration with Grice's conversational maxims. Such an attempt was for the purpose of taking into consideration the importance of pragmatic competence in her theory. Under her first rule, "be clear," she subsumed Grice's maxims for the reason that they are mainly related to the intention of making speech clear.

Accordingly, Lakoff (1973) argued that clarity warrants that the speaker be clear in his speech and communicate his message clearly. Therefore, since Grice's conversational maxims are mainly concerned with the message communicated clearly without ambiguity, Lakoff (1973) subsumed them under her first rule. On the other hand, Lakoff (1973) claimed that politeness, which is the second rule in her theory, focuses on the social factors that govern the communication among interlocutors in a particular situation. As a result, these two rules may have the same effect though they are fundamentally and functionally different. For this reason, Lakoff (1973) made a clear distinction between them in that the first rule concerns Grice's maxims, while the second rule of politeness was classified into sub rules, which are "don't impose, give options, and make a feel good and be friendly" (Lakoff, 1973). She explained that the first sub-rule is related to the distance and formality that join participants of the same or different societies together in a certain act of communication. Whilst the second takes into account the deference when addressing others. The last, however, 
concerns the addressee's feeling through interaction in that it is necessary for the addresser to be friendly with his addressee.

Lakoff's (1973) theory was criticised by Reiter (2000, p. 7), who pointed out that her rules about politeness could be universal to all cultures. However, what contradicted her universality of politeness was that when Lakoff (1975) modified her theory, she did not differentiate her terms from each other. She confused 'formality' with 'aloofness,' 'deference' with 'giving opinions,' and 'camaraderie' with 'showing sympathy.' Reiter (2000) emphasised the need to clearly define aloofness, deference, and camaraderie, abstracted from formality and showing sympathy. This is on the grounds that formality and showing sympathy have a great role in identifying how politeness could be expressed in a particular society or group and could not be considered universal.

In the same vein, Brown (1976, p. 246) highlighted that Lakoff's $(1973,1975)$ theories of politeness were not suitable as a universal theory because the terms of politeness used in these theories were not integrating each other, which is necessary and important in social relationships among interlocutors. In the same sense, Tannen (1984) argued against the universality of Lakoff's $(1973,1975)$ rules of politeness on the grounds that her use of terms such as 'informal' and 'aloof' were questionable. She emphasised that they were not universal, but cultural-specific. Besides, politeness is not a narrow phenomenon that can be controlled or accounted for in terms of a finite number of rules. In light of this, Watts (2003) stated that Lakoff's $(1973,1975)$ theory of politeness lacks the characteristics that speakers could follow in order to produce polite utterances as it lacks the characteristic of integration of politeness terms. Franck (1980), critically opined that Lakoff $(1973,1975)$ might not have paid attention to the difference between literal meaning and intended meaning in expressing any act. So, advocating those rules would result in a misconception on behalf of the addressee on the basis that he might lose the intended meaning implied within the message that the addresser wanted to convey or communicate.

Consequently, Lakoff's $(1973,1975)$ theory of politeness is not integral on the ground that the terms used to express politeness are confusing and not integrating each other. Furthermore, since politeness is a universal phenomenon and requires a non-finite number of rules to account for, it is not adequate to generalize Lakoff's (1973, 1975) rules of politeness to all cultures and languages as they are limited and not universal.

\section{Brown and Levinson's (1987) theory of politeness}

The most prominent work in the context of interlanguage pragmatic research, which was widely used, was the theory of politeness proposed by Brown and Levinson (1978, 1987) (Brunet, Cowie, Donnan, \& Douglas-Cowie, 2012, p. 2). The theory mainly focused on how politeness is expressed to protect participants' face. Brown and Levinson (1987) based their theory on Goffman $(1955,1967)$, who was the first to introduce positive face and indicated its importance and necessity in any particular social interaction (Brunet et al., 2012, p. 2). However, Brown and Levinson (1987) were more apparent in their treatment of face. They emphasised two ways of portraying the concept of face. The first way dealt with face from a positive and negative points of view, while the second concentrated on the claim that positive and negative faces represent interlocutors' steady wants.

Brown and Levinson (1987) extended the idea of 'face' into politeness. They viewed politeness as a concept with two characteristics: positive and negative. 'Positive politeness' is used to refer to what can be communicated to satisfy the needs of positive face while 'negative politeness,' on the other hand, functions in two ways. First, it can be expressed to save the "interlocutor's face" negatively or positively and second, it can be expressed by fulfilling the requirements of the negative face by the way of showing respect to the addressee and bearing in mind that his rights must be respected and "not to be imposed on" (Kitamura, 2000, p. 1). In this regard, for interlocutors to maintain their face, they cooperate with each other in any social communication as the need to maintain everyone's face relies on others (Wijayanto, Laila, Prasetyarini, \& Susiati, 2013).

Accordingly, Brown and Levinson (1987) proposed their strategies of politeness to protect interlocutor's face when expressing their speech acts in any social interaction. They claimed that these strategies may be universal to help speakers take account of the social factors involved with the speaker maintaining others' face through his use of speech acts. The importance of social factors in clarifying politeness strategies has compelled the researchers to shed light on them before explaining politeness strategies.

Brown and Levinson (1987) focused on three social factors that speakers should consider when interacting with each other. They are: 1) power, 2) social distance, and 3) the degree of imposition. Power refers to the social status of both speaker and hearer. The social distance is defined as the factor that indicates the degree to which interlocutors are familiar with each other (Brown \& Levinson, 1987). Kida (2011, p. 183) stated that social distance can be expressed by using different linguistic forms to indicate "respect, deference, and politeness." Meanwhile, the degree of imposition indicates the rank that an addresser enjoys and his ability to impose his ideas and desires on others. In the same sense, Martinze-Flor (2007, p. 6) argued that the degree of imposition is related to the way in which the speaker can impose his intention on the hearer. Consequently, it is necessary to take these social factors into consideration when expressing any speech act appropriately according to the social context because they control the preferred linguistic forms used. Wang, Johnson, \& Gratch (2010, p. 2) argued that, to be highly polite, this depends on the "potential threat of a communicative act." They pointed out that the factors involved in evaluating face threats as proposed by Brown and Levinson (1987) might affect the politeness strategies used to express certain speech acts.

Along the same line, Scollon and Scollon (2001) replicated, to some extent, Brown and Levinson's (1987) definition of the social factors as a vertical relationship that takes place between participants not from the same level or status (2001, 
p. 52). Concerning the second factor, which is social distance, it is important not to confuse distance with the difference in the social power between participants. This is due to the fact that not all hierarchical relationships involve a social distance between participants. For instance, sometimes, two persons have a hierarchical relationship between them because, for example, one is a manager, while the other is an assistant manager, but they know each other well, they meet each other every day, and they work together such that there is no distance between them (Scollon \& Scollon, 2001, p. 53). Therefore, it is not a must to associate the hierarchical structure relationships with social distance. It is not right to say that whenever there is a hierarchical relationship between participants, there is social distance.

Consequently, social norms play an important role in determining the social strategies of politeness used to express speech acts appropriately. However, since every language has its own way of conveying messages, intentions, and expressing different speech acts that may threaten face positively or negatively, four politeness strategies were proposed by Brown and Levinson (1987) to act as a guide that controls everyday threats of face with respect to social norms (Lambert, 1996, pp. 6-7). These strategies are: 1) bald on-record, 2) redress on-record, 3) off-record, and 4) do not do the act (Lambert, 1996, p. 7). The first strategy of bald on-record requires that the speaker be direct and clear in his expression of any speech act in any particular situation. This means that it is necessary for the speaker to use downgrades and upgraders to hedge his utterance.

As for the second strategy, Lambert (1996, p. 7) classified redress on-record into two forms of politeness: positive and negative. Following the redress on-record strategy, the speaker performs his action unambiguously. Also, he uses certain verbal actions to "minimize the damage done by the unambiguous commission of FTA" (henceforth facing threatening Act) (Lambert, 1996, p. 7). This can be achieved in terms of the two forms: positive and negative. The third strategy, the off-record act, means doing the act implicitly or indirectly. The fourth strategy, which is not to do the act, means that the speaker can avoid doing certain acts in a particular situation (Lambert, 1996, p. 7).

Despite the elaborate features and its wide application in many studies (Matsumoto, 1989; Ide, 1989; Gu, 1990, Mao, 1994; Kitamura, 2000; Haugh, 2005, Chen, 2010), Brown and Levinson's theory of politeness was not immune to criticisms. Their claims about universality of politeness and face is questionable. Brown and Levinson (1987, pp. 16162) stated that it is right that the two types of face are subject to cultural and social variants, but still they imply necessary social validity that may be applicable in different cultures and may overcome the cultural boundaries of the world. They feel that the variation of culture has no effect on the face to be positive or negative, and that cultural variation governs only the evaluation of whether a certain speech act is positive or negative (Mao, 1994, p. 471). In reaction to this claim, Matsumoto (1989) held that for Brown and Levinson (1987) to generalise their theory, they should consider non-Western cultures as their theory seems to focus only on expressing politeness in Western societies and cultures. Similarly, Ide (1989) argued that Brown and Levinson centered their focus only on how individuals express their speech acts politely. They should also pay attention to the group identity within a society. Furthermore, they should take into account how politeness functions in non-Western cultures. Consequently, in agreement with Matsumoto (1989), Ide (1989) opined that Brown and Levinson's (1987) politeness theory might not be adequate and suitable for a culture such as Japanese as the Japanese use politeness strategies in a way that is different from the Westerners.

To compare the concepts of face proposed by Brown and Levinson (1987) with that proposed by Mao (1994), different meanings and attitudes towards the treatment of face through expressing an act of communication can be recognised. Mao (1994) agreed with Gu (1990) about the argumentation discussed against Brown and Levinson's (1987) theory, i.e., threatening face saving depends not only on the rank and reputation of the person isolated from morals in a given context but rather may depend on the reputation and respect that a person has through his coexistence with others in his community. What they refer to is the morals and reputation that persons ascribe in life but not by their rank or position in society.

In his study, Mao (1994) attempted to challenge Brown and Levinson's (1987) universality of face conceptualisation and whether it could be manifested across cultures other than Western. In addressing this issue, he examined the differences between the Chinese face and Japanese, and Brown and Levinson's (1987) face.

Mao's analysis revealed that the Chinese face is different from Brown and Levinson's face in two points: conceptualisation and structure (Mao, 1994). From the conceptual point of view, Mao (1994) stated that Chinese face refers to the reputation and respect an individual can acquire through his interaction with others in a particular community. In this sense, individuals can be evaluated as entities that are affected and predetermined by the social norms which control the community in which they live. As for the structure of face, it is, according to Brown and Levinson (1987), classified into positive and negative. In contrast, Mao (1994), divided it into mianzi and lian. Unlike Brown and Levinson's (1987) negative face, mianzi is viewed in a different way to refer to one's prestige and reputation affected by external impositions. This is due to the claim that Chinese face is evaluated with regard to the external social norms that affect individuals in a group or community (Mao, 1994, p. 461). As for lian, it resembles, to a certain extent, Brown and Levinson's (1987) positive face in that both share the same characteristic of identifying "an individual's desire to be liked and to be approved of by the others" (Mao, 1994, p. 461). Despite this degree of resemblance between lian and Brown and Levinson's positive face, a distinctive feature still exists between them, which is the lack of moral tone in the positive face. Consequently, Mao (1994) indicated that it is not adequate to advocate the universality of Brown and Levinson's (1987) face to all cultures.

The second attempt made by Mao (1994) to elaborate his objection to the universality of Brown and Levinson's (1987) face was the identification of the Japanese face. His findings revealed that similar to the Chinese culture, Brown and 
Levinson's concept of face is not familiar in Japanese culture (Mao, 1994, p. 467). Consequently, Mao (1994, p. 467) concluded that there was a sort of resemblance between the Japanese concept of face and the Chinese face in that both, unlike Brown and Levinson's (1987) concept of face, focused on the public image of face and the community as an evaluator of one's desire, which made it different from the notion of the negative face proposed by Brown and Levinson.

To sum up, Mao (1994), in his study, revealed some points that cast doubt on the aspect of universality claimed by Brown and Levinson (1987). First, it has been shown that the universality of face proposed by them seemed to be inadequate and unjustified. Besides, the model of "face" as proposed by Brown and Levinson (1987) was also not appropriate to be adopted by the Japanese culture. Consequently, Mao (1994) proposed the positive and negative face, in addition to "the relative face orientation construct" (Mao, 1994, p. 483). Wierzbicka (1991) claimed that Brown and Levinson's (1987) theory is a reflection of perspectives and beliefs they bear in mind about Anglo culture. In the same sense, it has been argued that independence as a characteristic of the negative face, according to Brown and Levinson, was based on placing a high value on the individual in American and European cultures, but is not a basic feature in East Asian culture (Gu, 1990; Hill, Beverly, Sachiko, Ide, Shako, Ikuta, Akiko, Kawasaki, Tsunao \& Ogino, 1986; Ide, 1989; Matsumoto, 1989).

In another study, Kitamura (2000) investigated how Brown and Levinson's (1987) theory of politeness might not account for non-goal-oriented interaction, though it could be adopted in such interaction. He adapted Brown and Levinson's (1987) politeness strategies in his study of Japanese interaction in order to assess the suitability of Brown and Levinson's politeness theory to non-goal-oriented interactions and goal-oriented ones. The roles of the interactors were assigned in the selected segment of conversations. One of the interactors represented the involvement of the speaker who had the right to express his situation gradually by showing his respect to the hearer. On the other hand, the other interactor showed his involvement as a hearer by completing or summarising what had been said by the speaker. The findings showed that both interactors exhibited features not found in Brown and Levinson's theory of politeness, rather they were considered forms of politeness because they met the criteria of politeness proposed by Brown and Levinson (1987). Kitamura concluded that Brown and Levinson's politeness theory was also suitable for analysing politeness strategies in non-goal-oriented interactions. Taking this into consideration, it could be said that Brown and Levinson's (1987) theory of politeness was a theory of hearer orientation and not of the speaker.

Chen (2001) argued that Brown and Levinson (1987) might not consider the necessity of saving "one's own face." This means that they neglected the notion of self-politeness because they focused on how the speaker loses his face to save the addressee's face.

As a result, the challenges of the universality of Brown and Levinson's (1987) theory triggered a debate between the pragmatics of western and eastern cultures. Although much effort was exerted in the late 1980s by students of pragmatics to investigate how language is used in non-Western cultures, this effort was not intensified until much later (Chen, 2010), which led to the birth of the East-West pragmatics debate (Chen, 2010, p. 167).

Among those who triggered the debate was Chen (2010), who devoted a study to investigate whether East-West pragmatics was similar or different. Chen (2010) chose Japanese and Chinese languages to represent the Eastern hand of the debate and American English to represent the West. He attributed the reason for choosing Japanese and Chinese languages to represent the Eastern side to the fact that "they are the best studied Eastern languages" (Chen, 2010, p. 169).

In relation to Japanese pragmatics, Chen (2010) attempted to investigate whether Japanese pragmatics is different from or similar to that of English. His focus was centred on Brown and Levinson's (1987) theory of politeness and its appropriateness or inappropriateness to the Japanese. The findings revealed that what was suitable in terms of Brown and Levinson's (1987) theory for Anglo cultures might not be so for Japanese culture. In other words, Brown and Levinson's (1987) politeness theory might have failed to account for Japanese politeness (Matsumoto, 1989, p. 230).

In the same line, Haugh (2005, p. 44) challenged Brown and Levinson's (1987) politeness theory because it could not capture the way of politeness that Japanese used in expressing their speech acts. His argument was that for the speakers to be free from imposition in achieving their desires or approving their wants, it was not a problem or impolite according to Japanese pragmatics.

In contrast, certain studies have been conducted to advocate the notion that Japanese pragmatics is similar to that of the West by discussing four counter points (Usami, 2002; Pizziconi, 2003; Fukada \& Asato, 2004; Chen, 2010). First, it was found that Japanese showed their sensitivity towards Brown and Levinson's (1987) social factors (power, social distance, and the degree of imposition) in using honourifics in their language (Fukada \& Asato, 2004; Pizziconi, 2003; Usami, 2002). Second, it was indicated that the use of honourifics was proved to be sensitive to certain contextual social factors and was changing according to whether the situation was formal or informal (Fukada \& Asato, 2004; Pizziconi, 2003). Thus, such a way of dealing with honourifics is not different from that used in English (Pizziconi, 2003). Third, the greeting expression 'yoroshiku oregaishimasu,' is considered "deferential begging" to express gratitude to a person who is of a higher prestige than the speaker (Pizziconi, 2003). Fourth, Japanese speakers use "euphemisms, hedging, questioning, and apologising" in their speech acts to indicate their respect for the hearer (Pizziconi, 2003; Chen, 2010). In this light, the appreciation of the position of the hearer is considered an indication or a sign of using politeness strategies (Pizziconi, 2003). Consequently, the use of the negative face seems to be valid in Japanese culture as well as in Western cultures (Chen, 2010, p. 174). 
The second language which is considered the best representative alongside Japanese is Chinese. Researchers such as Gu (1990) Mao (1994), and (Chen, 2005) were interested in comparing the pragmatics of the Chinese language to that of the West. To indicate how Chinese pragmatics is different from the Western variety, it is necessary to refer to Gu (1990) and Mao (1994), who investigated the notion of difference by comparing Chinese politeness with that proposed by Brown and Levinson (1987). Gu (1990) found that Brown and Levinson's (1987) theory of politeness was not adequate for capturing the sense of politeness expressed by the Chinese. This was due to the claim that Brown and Levinson's politeness might not take into account the social norms apparent in the Chinese language which controlled the individual differently from other societies.

In contrast, the notion that Chinese politeness was similar to that of the English was held only by Chen (2005), who reanalysed his findings (1996). His findings showed that Chinese politeness is similar to Brown and Levinson's. This is due to the Western-like way of expressing politeness that the Chinese used to enhance and maintain the speaker and hearer's face. Consequently, Chen (2005) emphasised that despite the many differences highlighted between Chinese and Western pragmatics, they might not be differences deserving of debate between Western and Eastern pragmatics researchers.

However, Chen (2010), in his findings, showed that such a debate between Western and Eastern pragmatics was important for further investigation of cross-cultural pragmatics. It was also considered the basis for which different researchers could establish their works and studies about pragmatics (Chen, 2010, p. 181). Furthermore, such a debate has paved the way for the researchers of pragmatics to change their minds about the aspects of certain theories such as Speech Act Theory, Conversational Implicature Theory, and Brown and Levinson's (1987) Politeness Theory, which were subsumed under pragmatics (Chen, 2010, p. 181).

Accordingly, since there was dissatisfaction with some aspects of these classical theories, other theories and frameworks have appeared to uncover the mask that hides the pragmatic aspects of cultures other than non-Western culture. Among these theories and frameworks is Leech's (2005) newly proposed Grand Politeness framework which focuses on the "East-West cultural divide" (Leech, 2005, p. 1) of politeness. In this regard, the debate on the East-West politeness as a social phenomenon does not stop at the point of showing the differences and similarities in pragmatics between Western and Eastern cultures and languages, but rather proceeds to investigate the universal principles that help in explaining and discovering why such differences exist. Thus, it is necessary to conduct studies on the appropriateness of these new underlying theories in different cultures.

\section{Leech's theory of politeness}

Although considered an outstanding and influential theory in "cross-cultural and cross-linguistic contrastive pragmatics" (Leech, 2005, p. 1), Brown and Levinson's $(1978,1987)$ Theory of Politeness was not without criticism. As discussed in the previous section, critics such as Gu (1990), Ide (1989, 1993), Mao (1994), and Matsumoto (1989) have provided arguments against Brown and Levinson's theory. These critics found that the theory is Western biased in constructing the concept of face. As a result, the theory is seen as not being applicable in Eastern culture. This has led Leech (2005) to propose his new theory and investigate whether or not there is an East-West divide in politeness.

To argue against or for this debate, Leech (2005) presented an inclusive framework which combined a "common principle of politeness" (Leech, 1983, p. 2002) and a "Grand Strategy of Politeness" (Leech, 2005) in order to study politeness in speech acts such as "requests, offers, compliments, apologies, thanks, and responses to these" (Leech, 2005, p. 1). According to Leech's (2005) Grand Strategy of Politeness for a speaker to be polite he should take into consideration two constraints while communicating with others: 1) the major constraint which involved the speaker to "place a high value on what relates to the other persons," and 2) the minor constraint which also involved the speaker to "place a low value on what relates to him" (Leech, 2005, p. 1). Leech's (2005) theory might be applied and adopted to explain politeness in any act of communicative interaction in "Eastern languages such as Chinese, Japanese, and Korean, as well as in Western languages such as English” (Leech, 2005, p. 1).

In this regard, Leech (2005) argued that his theory is one of pragmaticism (1983) and goes hand in hand with Brown and Levinson's (1987) theory as both have their own influential roles in pragmatic studies and have remained outstanding theories despite all the criticisms that had been directed against them. For the time being, in his theory, Leech (2005) argued against the universality of Brown and Levinson's (1987) theory of politeness. His criticism focused on the applicability of the model to Westerners and its unsuitableness to "Eastern cultures and languages" (Leech, 2005). Leech also questioned Brown and Levinson's definition and classification of face into negative and positive, which was claimed to be based on Goffman's concept of face (Leech, 2005, p. 2; Schmidt, 1980, p. 104). He also reacted against Wierzbicka's (2003) principles of politeness, which are based on the universality of Brown and Levinson's (1987) politeness theory (2005, p. 3).

Similar to Brown and Levinson (1987), Leech (1983) was also criticised and accused of being biased towards Western cultures. The criticism was based on several reasons. First, Leech's (1983) maxims and approach of politeness are based on Grice's model of cooperative principles, which has been criticised for its vagueness and contradiction (Thomas, 1995, p. 168). Second, the criticism was directed toward the large and unjustified number of maxims proposed by Leech (1983), for if such a number was permitted, no one would control the addition of new 'counter examples' (Brown \& Stephen, 1987, p. 4). Finally, Leech's principles of pragmatics (1983) were criticised because they were based on Western cultures. In addition, there was too much attention paid to the 'tact maxim,' which focuses on mitigating the force of speech acts on behalf of the interlocutors. 
Out of all the criticism set out against Leech's (1983) principles of pragmatics, an attempt was made by Leech (2005) to reformulate his earlier proposed maxims of politeness, which were "tact, generosity, approbation, modesty, agreement, and sympathy" (Leech, 2005, p. 12). The term "maxim" is no longer favoured as it concerns moral rather than pragmatic constraints, which leads to a misunderstanding of the meaning intended by the speaker (Leech, 2005, p. 12; Thomas, 1995, p. 168). Thus, according to Leech (2005), it is necessary and important to propose a new constraint in order to comprehend the previous maxims and the pragmatic constraints. As a result, he called for a new single constraint, referred to as the Grand Strategy of Politeness. This is regarded as the 'super constraint' under which all maxims of politeness are subsumed. Its main concern is to estimate the value of the speaker and the hearer.

Although considered not universal, Leech's (2005) Grand Strategy of Politeness remains workable among people from different cultures and languages (Leech, 2005, p. 4). He reformulated the politeness maxims proposed earlier and modified them into ten new maxims, paying attention to their applicability to all cultures.

Despite these modifications, it is a fact that politeness is not constant in all situations. Different degrees of politeness may occur in interaction, and these may be influenced by different social factors such as 1) vertical distance between the speaker and hearer; 2) horizontal distance, which is identified in terms of the intimacy, familiarity, solidarity, and the deference relations between the speaker and the hearer (2005); 3) weight or value, which refers to the social distinction attached to what is transacted; 4) strength of socially defined rights and obligations, which refers to the relation between teacher and student, a lover and his lover, host and guest; and 5) 'self-territory' and 'other-territory,' which refer to the degree of memberships of in-groups and out-groups. According to Brookins (2010), two social variants are involved in such a social scale, which are social groups in which the exclusion of others from the interactions means that the speaker is less polite, and romance, in which the speaker is more polite with those included and "less polite towards those not included in his romance" (Brookins, 2010, p. 1293).

Brookins (2010) attempted to apply Leech's (2005) Grand Strategy of Politeness across "the chronological divide between antiquity and modernity." He assessed the "directive/imposition" speech acts and commissives in the polite and impolite language of Catullus' plyometric poems (1-60), and Leech's (2005) five scales to measure the degree of politeness that was appropriate to use. The study showed that all the five scales had the same value in determining politeness in a given poem. It also revealed that Leech's (2005) politeness is appropriate to antiquity as well as to modernity. On this basis, it can be argued that Leech's (2005) politeness is appropriate to literary texts as well as communicative texts.

Dybko (2010) conducted a study on how politeness functions in the language of headlines. The study aimed to investigate the effectiveness of Leech's (2005) Grand Strategy of Politeness in exploring the language of advertisement. A number of actual slogans, which were used for the purpose of advertisement, were selected in this study. Leech's (2005) model was used to analyse the selected slogans. The findings revealed that Leech's (2005) Grand Strategy of Politeness framework seems to be the most applicable and "effective instrument" (Dybko, 2010, p. 26) in the analysis of advertisements used in headlines. This is because of the various linguistic and social aspects it offers in interaction between individuals of a society, which make it seem universal to all cultures and applicable to most speech acts such as request, apology, and complaint. Chen, $\mathrm{He}$, and $\mathrm{Hu}$ (2013) in their study on requests made in American English, Japanese, and Chinese, agreed with Leech's (2005) claim that there is no difference between the Eastern politeness system and the Western version. However, since Leech's (2005) framework of politeness proved its universality in different cultures as Western and Eastern, its strategies are not immune to use in different acts of communications in different languages.

In 2011, Matsuoka, Smith, and Uchimura conducted a study to investigate the use of encouragement by healthcare professionals on their patients. They used Leech's Grand Strategy of Politeness $(2005,2009)$ to analyse the utterances used by healthcare professionals in encouraging patients. The results showed that each verbal utterance of encouragement was associated with a strategy of politeness from Leech's $(2005,2009)$ model. The findings also suggest that Leech's theory of politeness is helpful and effective in providing situations of encouragement with the appropriate strategies that make communication successful and of high quality. Accordingly, this may support Leech's (2005) framework of politeness which stresses the use of different strategies appropriate to different situations.

Matsuoka and Poole (2015) replicated Matsuoka et al.'s (2011) study to investigate the effective role of Leech's (2005, 2009) politeness strategies in the healthcare professionals' discourse when interacting with their patients and patients' families at difficult times. The findings revealed that Leech's $(2005,2009)$ Grand Strategy of Politeness seems the most effective and helpful framework, which enhances high-quality-interaction between the interlocutors concerned. Furthermore, the results also showed that Leech's politeness strategies were available in each scene of healthcare utterance. In addition, the findings reported applicability of Leech's theory to the Eastern as well as Western culture, which emphasizes that Leech's strategies seem to be appropriate to different contexts as well as cultures.

Bearing the aforementioned arguments in mind, it is just to claim that Leech's framework (2005) is appropriate to both Eastern and Western cultures because it takes into account how politeness is used in the East by Japanese, Chinese, and Koreans, and how it is used in the West. Furthermore, it is speaker- and hearer-oriented, and covers most of the social variants that influence the choice of politeness strategies.

\section{Conclusion}

This paper was designed to provide a critical review on the most prominent theories of politeness of Brown and Levinson, 1987; Lakoff (1973, 1975); and Leech (2005), and discuss any shortcomings and/or merits of each theory. It 
also was designed to argue with or against the universality of a theory of politeness to all cultures. The following conclusions can be drawn from this paper. First, it has argued for the lack of universality and applicability of Brown and Levinson's (1987) theory of politeness to all cultures. This is evident in much of the criticisms that have been directed toward Brown and Levinson (1987) because of their claim about the universality of their theory and their Western-bias and the hearer-oriented, and focus on the "Western individual-orientation." Second, the paper has also showed that Lakoff's $(1973,1975)$ theory of politeness seems confusing and is not integral on the basis that it may not meet the demands of politeness as a universal phenomenon. This may be attributed to the use of the confusing terms and the limited number of rules in expressing politeness.

Third, as for Leech's (2005) Grand Strategy of Politeness framework, this paper suggests that it is applicable to and can explain any communicative politeness in languages of the East as well as of the West. As stated earlier, the theory seems appropriate to and effective in most, if not all, languages and cultures. This is because it covers most of the social variants that influence the choice of politeness strategies, and it has various aspects that suit most types of discourse and situation. Furthermore, it is speaker- and hearer-oriented. Accordingly, Leech's (2005) framework of politeness seems universal and applicable to most cultures and speech acts. This supports Dybko's (2010) study which concluded that Leech's (2005) framework of politeness seems "to be the most universal model of linguistic politeness" (Dybko, 2010, p. 24).

\section{References}

Ashizuka, A., Mima, T., Sawamoto, N., Aso, T., Oishi, N., Sugihara, G., \& Fukuyama, H. (2015). Functional relevance of the precuneus in verbal politeness. Neuroscience research, 91, 48-56.

Brookins, T. A. (2010). A politeness analysis of Catullus' polymetric poems: Can Leech's GSP cross the ancientmodern divide? Journal of Pragmatics, 42(5), 1283-1295.

Brown, P. (1976). "Women and politeness: A new perspective on language and society. Review of 'Language and woman's place' by R. Lakoff'. Reviews in Anthropology 3: 240-249.

Brown, P., and Stephen, L. (1987). Politeness: Some Universals in Language Use. Cambridge: Cambridge University Press.

Brunet, P. M., Cowie, R., Donnan, H., \& Douglas-Cowie, E. (2012). Politeness and social signals. Cognitive processing, 13(2), 447-453.

Chen, R. (2001). Self-politeness: a proposal. Journal of Pragmatics 33, 87--106.

Chen, R. (2005). Universalism vs. particularism: whither pragmatics? Modern Foreign Languages 28, 120--128.

Chen, R. (2010). Pragmatics between east and west: similar or different? In: Trosborg, Anna (Ed.), Pragmatics across Languages and Cultures (Handbooks of Pragmatics 7). Mouton de Gruyter, Berlin/New York, pp. 167--188.

Chen, R., He, L., \& Hu, C. (2013). Chinese requests: In comparison to American and Japanese requests and with reference to the "East-West divide". Journal of Pragmatics, 55, 140-161.

Dybko, K. (2010). The Role of Politeness in Advertisements' Slogans: A Study within Gricean Pragmatics. ACTA PHILOLOGICA, 20.

Eelen, G. (2001). Critique of Politeness Theories. St. Jerome Press, Manchester.

Goffman, E. (1967). Interactional Ritual: Essays on face-to-face behavior. Garden City, NY: Anchor Books.

Ermida, I. (2006). Linguistic mechanisms of power in Nineteen Eighty-Four: Applying politeness theory to Orwell's world. Journal of pragmatics, 38(6), 842-862.

Fairclough, N. (1989). Language and Power. New York: Longman.

Franck, D. (1980). Grammatik und Konversation. Dusseldorf.

Fukada, A., \& Asato, N. (2004). Universal politeness theory: application to the use of Japanese honorifics. Journal of Pragmatics, 36(11), 1991--2002.

Grice, H. P., Cole, P., \& Morgan, J. L. (1975). Syntax and semantics. Logic and conversation, 3, 41-58.

Gu, Y. (1990). Politeness phenomena in modern Chinese. Journal of Pragmatics, 14(2), 237--257.

Haugh, M. (2005). The importance of "place" in Japanese politeness: implications for cross-cultural and intercultural analysis. Intercultural Pragmatics, 2(1), 41--68.

Hill, B., Sachiko, I., Shako, I., Akiko, K, Tsunao \& Ogino. R. (1986). Universals of linguistic politeness: quantitative evidence from Japanese and American English. Journal of Pragmatics, 10(3), 347--371.

Holmes, J. (1995). Women, Men and Politeness. New York: Longman.

Holmes, J. (2001). An Introduction to Sociolinguistics. Edinburgh: Longman.

Ide. D. (1989). Formal forms and discernment: two neglected aspects of linguistic politeness. Multilingua, 8, $223-248$. 
Kida, I. (2011). Language distance across cultures as a way of expressing politeness and not only. In Aspects of Culture in Second Language Acquisition and Foreign Language Learning (pp. 183-191). Springer Berlin Heidelberg.

Kitamura, N. (2000). Adapting Brown and Levinson's 'politeness' theory to the analysis of casual conversation. In Proceedings of ALS2k, the 2000 Conference of the Australian Linguistic Society (pp. 1-8).

Lakoff, R. (1973). The logic of politeness: or minding your p's and q's. In: Papers from the Ninth Regional Meeting of the Chicago Linguistics Society, pp. 292--305.

Lakoff, R. (1973). Language and woman's place. Language in society, 2(01), 45-79.

Lakoff, R. (1975). Language and Woman's Place. New York: Harper and Row.

Lambert, B. L. (1996). Face and politeness in pharmacist-physician interaction. Social science \& medicine, 43(8), 11891198.

Leech, G. (1983). Principles of pragmatics. London and New York: Longman.

Leech, G. (2005). Politeness: is there an East-West divide. Journal of Foreign Languages, 6(3).

Leech, G. (2007). Politeness: is there an East-West divide? Journal of Politeness Research, 3(2), 167--206.

Mao, R. (1994). Beyond politeness theory: “face” revisited and renewed. Journal of Pragmatics, 21(5), 451--486.

Martínez-Flor, A. (2007). Analysing request modification devices in films: Implications for pragmatic learning in instructed foreign language contexts. In Intercultural language use and language learning (pp. 245-280). Springer Netherlands.

Matsuoka, R., \& Poole, G. (2015). Politeness Strategies in Healthcare Communication at" Difficult Times": A Pragmatic Analysis of the" Manga" Discourse in" Nurse Aoi". Journal of Pan-Pacific Association of Applied Linguistics, 19(2), 89-109.

Matsuoka, R., Smith, I., \& Uchimura, M. (2011). Discourse Analysis of Encouragement in Healthcare Manga. Journal of Pan-Pacific Association of Applied Linguistics, 15(1), 49-66.

Matsumoto, Y. (1989). Politeness and conversational universals: observations from Japanese. Multilingua, 8, $207--221$.

Mills, S. (2003). Gender and Politeness. Cambridge, Cambridge University Press.

Pizziconi, B. (2003). Re-examining politeness, face and the Japanese language. Journal of Pragmatics, 35(10/11), 1471--1506.

Reiter, R. M. (2000). Politeness in Britain and Uruguay: A Contrastive Study of Requests and Apologies. John Benjamins B.V.

Scollon, R., \& Scollon, S.W., (2001). Intercultural Communication: A Discourse Approach. Blackwell, Oxford.

Sperber, D., and Wilson, D. (1987). Relevance. Cambridge, MA. Harvard University Press.

Tannen, Deborah (1984) Conversational Style: analyzing talk among friends. Norwood, NJ: Ablex.

Terkourafi, M. (2005). An argument for a frame-based approach to politeness.Broadening the horizon of linguistic politeness, 139, 99.

Thomas, J. (1995). Meaning in Interaction. New York: Longman.

Usami, Mayumi, 2002. Discourse Politeness in Japanese Conversation: Some Implications for a Universal Theory of Politeness. Hituzi Syobo, Tokyo.

Wang, N., Johnson, W. L., \& Gratch, J. (2010). Facial expressions and politeness effect in foreign language training system. In Intelligent Tutoring Systems (pp. 165-173). Springer Berlin Heidelberg.

Watts, R.J. (2003). Politeness. Cambridge University Press, Cambridge.

Wierzbicka, A. (1991). Cross-cultural Pragmatics. The Semantics of Human Interaction. Mouton de Gruyter, Berlin and New York.

Wierzbicka, A. (1992). Semantics, Culture, and Cognition: Universal Human Concepts in Cultural-Specific Configurations. New York: Oxford University Press.

Wierzbicka, A. (2003). Cross-Cultural Pragmatics: The Semantics of Human Interaction (2nd edn.) Berlin/New York: Mouton de Gruyter.

Wijayanto, A., Laila, M., Prasetyarini, A., \& Susiati, S. (2013). Politeness in Interlanguage Pragmatics of Complaints by Indonesian Learners of English.English Language Teaching, 6(10), p188.

Yoshimura, Y., \& MacWhinney, B. (2011). Honorifics: A sociocultural verb agreement cuein Japanese sentence processing (vol. 31, p. 551, 2010). Appl. Psycholinguist, 32,243-244. 